\title{
Cycling of NMDA Receptors during Trafficking in Neurons before Synapse Formation
}

\author{
Philip Washbourne, Xiao-Bo Liu, Edward G. Jones, and A. Kimberley McAllister \\ Center for Neuroscience, University of California Davis, Davis, California 95616
}

\begin{abstract}
The trafficking of glutamate receptors in neurons is of the utmost importance for synapse formation and synaptic plasticity. Recently, we demonstrated that both NMDA and AMPA receptors reside in mobile transport packets that are recruited rapidly and independently to nascent synapses. Here, we show that a large proportion of the glutamate receptor clusters in young cortical neurons are present on the surface of dendrites before synapses are formed and these surface-exposed transport packets are mobile. Exocytosis of glutamate receptors to the dendritic surface occurs via a SNARE [soluble $n$-ethylmaleimide-sensitive factor attachment protein (SNAP) receptor]dependent SNAP-23-mediated mechanism. Endocytosis occurs rapidly after surface exposure; $>50 \%$ of surface-labeled NMDA receptors (NMDARs) are endocytosed within $5 \mathrm{~min}$. NMDARs are transported along microtubules on large tubulovesicular organelles, as indicated by immunoelectron microscopy, and are associated with EEA1 (early endosomal antigen 1) and SAP102 (synapse-associated protein 102), as indicated by immunocytochemistry. Most surprisingly, a large proportion of these transport packets cycle through the dendritic plasma membrane before synapse formation. These results suggest a novel model in which NMDARs cycle with the plasma membrane during pauses of movement along microtubules while trafficking.
\end{abstract}

Key words: development; glutamate; cortex; synaptogenesis; dendrite; transport

\section{Introduction}

During development of the CNS, sites of contact between axonal and dendritic processes are transformed into structures for highly specialized communication called synapses. The cellular processes involved in the formation of synapses are only just beginning to be understood (for review, see Ziv and Garner, 2001; Cohen-Cory, 2002). One of the most critical events in synaptogenesis of glutamatergic synapses is the recruitment of ionotropic glutamate receptors, the primary mediators of excitatory synaptic transmission in the CNS. To investigate the mechanisms of glutamate receptor recruitment to new synapses, the mechanisms of glutamate receptor trafficking before synapse formation must first be delineated, because this trafficking must be modified during recruitment of glutamate receptors to, and stabilization at, new synapses.

Before becoming localized to synapses, newly synthesized NMDA receptors (NMDARs) must assemble, mature, and be transported into the dendrites. NMDARs are composed of NR1 and NR2 subunits (Hollmann and Heinemann, 1994) that as-

Received March 5, 2004; revised Aug. 2, 2004; accepted Aug. 3, 2004.

This work was supported by the Alfred P. Sloan Foundation, the Pew Charitable Trusts, the March of Dimes, and National Institutes of Health Grant R01 EY13584 (A.K.M.). P.W. was a scholar of the Institute for the Medical Investigation of Neurodevelopmental Disorders (Davis, CA). We thank R. Jacobs (Salk Institute, San Diego, CA) for performing EM on cultured neurons, F. El-Sabeawy (University of California Davis, Davis, CA) for maintenance of neuronal cultures, L. N. Clark (University of California Davis) for optimizing the Zenon-labeling protocol, J. Wenzel (University of California Davis) for help evaluating EM images, R. Wenthold (National Institutes of Health, Bethesda, MD) for the anti-SAP102 antibody, and S. Vicini (Georgetown University, Washington, DC) for NMDAR constructs and critical reading of this manuscript.

Correspondence should be addressed to Dr. A. Kimberley McAllister, Center for Neuroscience, 1544 Newton Court, Davis, CA 95616. E-mail: kmcallister@ucdavis.edu.

D01:10.1523/JNEUROSCI.2555-04.2004

Copyright $\odot 2004$ Society for Neuroscience $\quad$ 0270-6474/04/248253-12\$15.00/0 semble in the endoplasmic reticulum (ER) to form functional channels (Monyer et al., 1994; McIlhinney et al., 1998; Ozawa et al., 1998). An ER retention signal within the $\mathrm{C} 1$ splice cassette of the NR1 subunit is thought to be masked by the proper assembly of NR1 and NR2 subunits, promoting the trafficking of functional receptors (McIlhinney et al., 1998; Standley et al., 2000; Scott et al., 2001; Xia et al., 2001). Our understanding of the transport of NMDARs becomes much less complete once the subunits are released from the ER and processed in the Golgi apparatus. In general, NMDARs are believed to be transported in clusters along microtubules (Washbourne et al., 2002b), and some of these NMDAR transport packets may be transported in vesicles by KIF17, a member of the kinesin protein superfamily (Setou et al., 2000; Guillaud et al., 2003).

Current models for NMDAR trafficking and recruitment to new synapses are based on the general rules for biosynthesis and membrane insertion of integral membrane proteins. After assembly in the ER and Golgi apparatus, transmembrane proteins are packaged into carrier vesicles and transported into dendrites. These carrier vesicles then deliver their contents by fusion with the plasma membrane (Craig and Banker, 1994). Correctly targeted proteins may then be stabilized in the membrane by interacting with scaffolding and cytoskeletal proteins that prevent their endocytosis (Roche et al., 2001).

Based on this general understanding of receptor trafficking, two models have been proposed to account for insertion of glutamate receptors into newly formed synapses (see Fig. 1A). The first model is the most prevalent: intracellular vesicular transport of NMDARs and insertion of NMDARs directly into synapses after a cue initiated by contact between an axon and a dendrite (Setou et al., 2000; Wenthold et al., 2003). Although less com- 
mon, the second model is equally plausible: insertion of NMDARs into the dendritic plasma membrane soon after transport out of the ER-Golgi pathway and lateral diffusion to a new site of synaptic contact (Tovar and Westbrook, 1999; Choquet and Triller, 2003). Resolution of this issue is important; the mechanism of transport of glutamate receptors has significant implications for which molecular signals may cause those receptors to be recruited to new sites of synaptic contact.

Here, we report experiments designed to determine the distribution of NMDARs and the mechanism of their transport in dendrites before synapse formation. Using a combination of time-lapse imaging, immunocytochemistry, biochemistry, and electron microscopy (EM), we demonstrate here that both of the proposed trafficking models are correct: NMDAR transport packets are actively exo/endocytosed through the dendritic plasma membrane before synapse formation. Our results suggest a novel model in which vesicles containing NMDARs cycle with the plasma membrane during pauses of movement along microtubules.

\section{Materials and Methods}

DNA constructs. HA-SNAP-25 [influenza A virus hemagglutinin (HA)tagged soluble $N$-ethylmaleimide-sensitive factor attachment protein (SNAP)-25] NR1-enhanced green fluorescent protein (EGFP), and EGFP-neuroligin1 (EGFP-Nlg1) have been described previously (Washbourne et al., 1999, 2002b; Fu et al., 2003). EGFP-NR1, enhanced cyan fluorescent protein-NR1 (ECFP-NR1), and EGFP-NR2B were gifts from S. Vicini (Georgetown University, Washington, D.C.). Clathrin light chain was obtained from T. Kirchhausen (Harvard Medical School, Boston, MA) and subcloned into pECFP-C1 (Clontech, Palo Alto, CA). The cDNAs for the light chains of botulinum neurotoxin (BoNT) types A and E were obtained from T. Binz (Medizinische Hochschule, Hannover, Germany) and subcloned into pIRES2-EGFP (Clontech). Mouse SNAP-23 was subcloned by PCR and inserted into pCDNA/HA (Washbourne et al., 1999). All PCR steps were checked by sequencing.

Neuronal culture and transfections. Neurons from rat cortex were cultured as described (Bekkers and Stevens, 1989) but were plated on astrocyte monolayers at a density of $22 \mathrm{~K} / 18 \mathrm{~mm}$ coverslip for live imaging and $11 \mathrm{~K} / 12 \mathrm{~mm}$ coverslip for immunocytochemistry. Neurons were transfected with Lipofectamine 2000 (Invitrogen, Carlsbad, CA) as described previously (Washbourne et al., 2002b), except that before addition of the DNA-liposome mix, culture medium was exchanged for medium without antibiotics.

Live-cell imaging. For labeling of endogenous NR1 with the antibody R1JHL (Affinity Bioreagents, Golden, CO), neurons were incubated with either Zenon One Alexa-488 directly labeled antibody (see below) or the antibody $(1: 100)$ for $30 \mathrm{~min}$ at $37^{\circ} \mathrm{C}$ followed by anti-mouse IgG Alexa488 for $30 \mathrm{~min}$.

Fab fragment was purified from $0.5 \mathrm{mg}$ of monoclonal anti-GFP antibody (Molecular Probes, Eugene, OR) using the Immunopure Fab preparation kit (Perbio, Helsingborg, Sweden) according to manufacturer's instructions. The Fab fragment was conjugated to Alexa-568 fluorophore using a monoclonal antibody labeling kit (Molecular Probes). Purity of Fab fragment was confirmed by SDS-PAGE (supplemental Fig. 1; available at www.jneurosci.org as supplemental material), and efficiency of labeling was monitored using a spectrophotometer. Coverslips (18 mm) were imaged in a custom-built imaging chamber (Warner, Hamden, CT) in artificial CSF (ACSF) (Washbourne et al., 2002b) 14-24 hr after transfection. Before mounting in the imaging chamber, neurons were incubated in culture medium with anti-GFP Fab fragment (1:200) or whole GFP antibody (1:500; Molecular Probes) for $10 \mathrm{~min}$ at $37^{\circ} \mathrm{C}$. In the case of full antibody, the medium was then exchanged with fresh medium containing an Alexa-568-labeled secondary antibody (1:250; Molecular Probes) for $10 \mathrm{~min}$ at $37^{\circ} \mathrm{C}$. For transferrin uptake experiments, neurons were incubated with Fab fragment (1:100) and transferrin-Alexa-647 (1:100; Molecular Probes) for 2 min, washed with ACSF, and immediately transferred to the imaging chamber. For acid-stripping experi- ments, neurons were cooled to $4^{\circ} \mathrm{C}$ for $10 \mathrm{~min}$, labeled with anti-GFP in ACSF for $10 \mathrm{~min}$, and then returned to $37^{\circ} \mathrm{C}$ in culture medium for varying periods to allow receptor cycling. Neurons were again cooled to $4^{\circ} \mathrm{C}$ for $5 \mathrm{~min}$, acid stripped for $60 \mathrm{sec}$ with $500 \mathrm{~mm} \mathrm{NaCl}$ and $200 \mathrm{~mm}$ acetic acid, pH 3 (Carroll et al., 1999), and returned to culture medium for $10 \mathrm{~min}$ with secondary antibody at $37^{\circ} \mathrm{C}$. Imaging was conducted on an Eclipse TE300 Nikon inverted fluorescence microscope using a $60 \times$ oil immersion objective [1.4 numerical aperture (NA)]. Fluorophores were excited at their absorption maxima using a TILL Photonics (Martinsried, Germany) monochromator combined with double and triple bandpass filters specific for CFP-DsRed and FITC-Texas Red-Cy5 (Chroma, Battleboro, VT). No significant signal was obtained from GFP using the CFP-DsRed filter when exciting at $435 \mathrm{~nm}$ at these expression levels. Furthermore, no bleed-through was noted between Alexa-568and Alexa-647-labeled probes at the concentrations indicated when using the FITC-Texas Red-Cy5 filter. These controls were conducted by using only one chromophore and checking all other wavelength and filter combinations for detectable signal. Images were acquired sequentially with a CoolSNAP HQ CCD camera (Roper Scientific, Tucson, AZ) and Simple PCI software (C-Imaging, Compix Inc., Cranberry Township, PA).

Immunocytochemistry. For immunocytochemistry with anti-NR1 antibody (54.1, 1:500; PharMingen, San Diego, CA), cells were fixed with methanol at $-20^{\circ} \mathrm{C}$ for $10 \mathrm{~min}$ as described previously (Washbourne et al., 2002b). Immunocytochemistry with a different antibody to NR1, R1JHL, was performed by fixing cells with $4 \%$ paraformaldehyde and $4 \%$ sucrose in PBS and then permeabilizing with $0.3 \%$ saponin, because Triton X-100 abolished labeling with this primary antibody. Neurons were then blocked with $10 \%$ BSA in PBS and incubated with primary and secondary antibodies in 3\% BSA. For surface and internal labeling of endogenous NR1 (see Fig. $1 B$ ), the antibody to NR1 (R1JHL) was directly labeled using Zenon One Alexa-488 and -568 mouse IgG Iabeling $_{1}$ kits (Molecular Probes) at a ratio of 1:6 for 5 min per manufacturer's instructions. Neurons were incubated with the Zenon-488-labeled antibody at $4^{\circ} \mathrm{C}$ for $10 \mathrm{~min}$ in ACSF. After washing, the cells were either incubated with the Zenon-568-labeled antibody for $10 \mathrm{~min}$ and fixed with methanol or fixed with methanol and then incubated with Zenon568 -labeled antibody in 3\% BSA for $10 \mathrm{~min}$. For surface labeling of GFP on transfected neurons, neurons were incubated with anti-GFP antibody as described for live imaging and then fixed with paraformaldehyde and sucrose for $10 \mathrm{~min}$ at $4^{\circ} \mathrm{C}$. Neurons were then permeabilized with $0.25 \%$ Triton X-100, and additional steps were conducted as described above. Primary antibodies used were as follows: synapsin (1:1000; Chemicon, Temecula, CA), MAP2 (1:1000; Sternberger Monoclonals, Lutherville, MD), NR2A (1:500; Upstate Biotechnology, Lake Placid, NY), NR2B (1:200; Chemicon), vesicular glutamate transporter 1 (1:2000, Chemicon), GluR1 (1:500; Upstate Biotechnology), SAP102 (1:1000; R. Wenthold, National Institutes of Health, Bethesda, MD), and EEA1 (1: 2000; BD Transduction Laboratories). Secondary antibodies used were anti-rabbit Alexa-647, anti-mouse Alexa-568, and anti-guinea pig Alexa647 (Molecular Probes). Mounted coverslips were imaged using an Olympus Fluoview 2.1 laser scanning confocal microscope with a $60 \times$ PlanApo oil immersion objective (1.4 NA) on an IX70 inverted microscope. Images for each fluorophore were acquired sequentially and averaged over two scans.

BoNT cleavage of SNAP-25 and SNAP-23. Chinese hamster ovary (CHO) cells were plated in six-well plates at 500,000 cells per well. The next day they were transfected with HA-SNAP-25-pCDNA3, or HASNAP-23-pCDNA3 and GFP, BoNT/A-IRES-GFP, or BoNT-E-IRESGFP using Lipofectamine 2000. The following day, cells were lysed in 150 mм NaCl, 20 mm Tris, 2 mm EDTA, 1\% Triton X-100, 0.05\% SDS, and protease inhibitors (Roche, Hertfordshire, UK). Protein in the lysate was precipitated with $80 \%$ acetone at $-20^{\circ} \mathrm{C}$, and the pellet was resuspended in Laemmli sample buffer. Electrophoresed samples were transferred to membranes, which were incubated with anti-HA1.1 (1:1000; Babco/ CRP, Richmond, CA) and HRP-conjugated secondary antibody. Detection was performed with ECL+ chemiluminescence and a STORM PhosphorImager.

Surface biotinylation. Surface biotinylation was performed as de- 
scribed previously (Ehlers, 2000). Cortical neurons were plated on astrocytes in $75 \mathrm{~cm}^{2}$ culture flasks and grown for $4 \mathrm{~d}$ in vitro (4 DIV). Leupeptin $(10 \mathrm{~mm})$ was added $30 \mathrm{~min}$ before biotinylation. Cells were cooled to $10^{\circ} \mathrm{C}$ in PBS with $1 \mathrm{~mm} \mathrm{CaCl}_{2}$ and $0.5 \mathrm{~mm} \mathrm{MgCl}_{2}$ (PBS++). Cells were incubated with $1.5 \mathrm{mg} / \mathrm{ml}$ sulfo-NHS-SS-biotin (Pierce, Rockford, IL) for $20 \mathrm{~min}$ at $10^{\circ} \mathrm{C}$. After quenching with $50 \mathrm{~mm}$ glycine and washing with $\mathrm{PBS}++$, cells were incubated in neuronal medium at $37^{\circ} \mathrm{C}$ for the times indicated. Cells were again cooled to $10^{\circ} \mathrm{C}$ and reduced with cleavage buffer (50 mm glutathione, $75 \mathrm{~mm} \mathrm{NaCl}, 10 \mathrm{~mm}$ EDTA, 1\% BSA, $0.075 \mathrm{~N}$ $\mathrm{NaOH}$ ) twice for $15 \mathrm{~min}$. After quenching with $5 \mathrm{mg} / \mathrm{ml}$ iodoacetamide, cells were then scraped in lysis buffer ( $50 \mathrm{~mm}$ Tris- $\mathrm{HCl}, 2 \mathrm{~mm}$ EDTA, 2 mM EGTA, and protease inhibitors), sonicated on ice for $30 \mathrm{sec}$, and centrifuged at $100,000 \times g$ for $20 \mathrm{~min}$. Pellets were resuspended in precipitation buffer (lysis buffer plus $100 \mathrm{~mm} \mathrm{NaCl}$ ), and $0.2 \%$ SDS was added and heated to $60^{\circ} \mathrm{C}$ for $5 \mathrm{~min}$. Then $1 \%$ Triton X-100 was added, and samples were sonicated for $20 \mathrm{sec}$ and centrifuged at $100,000 \times g$ for $20 \mathrm{~min}$. The resulting supernatant was incubated with BSA-blocked Ultralink-streptavidin beads (Pierce) at $4^{\circ} \mathrm{C}$ for $2 \mathrm{hr}$, washed four times with precipitation buffer with $1 \%$ Triton X-100, and then boiled with SDS-PAGE loading buffer. Samples were electrophoresed and immunoblotted for NR1 (54.1, 1:1000; PharMingen) and neuroligin (1:1000; Synaptic Systems, Goettingen, Germany) as described above.

Electron microscopy. For immunoelectron microscopy (immuno-EM) of cultured neurons, transfected cortical neurons were incubated with rabbit anti-GFP antibodies (1:250; Chemicon) and then anti-rabbit-IgG conjugated with $15 \mathrm{~nm}$ gold (EMS, Fort Washington, PA). After imaging, coverslips were fixed for 20 min with $4 \%$ glutaraldehyde in $0.1 \mathrm{M} \mathrm{caco}-$ dylate buffer. Cells were then postfixed with $1 \%$ osmium tetroxide for 20 min. After rinsing with cacodylate buffer, coverslips were dehydrated through an ethanol series to $70 \%$ ethanol, stained with uranyl acetate, and then further dehydrated in $100 \%$ ethanol. After transferring to propylene oxide, coverslips were infiltrated with Embed 812 (EMS) for $12 \mathrm{hr}$ and then hardened for $24 \mathrm{hr}$ at $60^{\circ} \mathrm{C}$. Coverslips were removed with hydrogen fluoride, and $60 \mathrm{~nm}$ sections were cut on an ultramicrotome, recovered on Formvar-coated single slot copper grids, and examined in a JEOL 100CX-II electron microscope at $80 \mathrm{kV}$. Electron micrographs were taken with a MegaView III digital camera (Soft Imaging System, Boulder, CO).

Cortical sections were prepared for electron microscopy as described previously (Golshani et al., 2001). Briefly, postnatal day 2 (P2) mice were perfused transcardially with cold saline followed by $4 \%$ paraformaldehyde and $0.1 \%$ glutaraldehyde in phosphate buffer, $\mathrm{pH}$ 7.4. Cortical sections $(500 \mu \mathrm{m})$ were cut on a vibratome. Small pieces of cortex were immersed in increasing concentrations of glycerol at $4^{\circ} \mathrm{C}$, plunged into propane cooled to $-180^{\circ} \mathrm{C}$, transferred to the precooled chamber $\left(-90^{\circ} \mathrm{C}\right)$ of a Leica AFS cryo-embedding unit, and infiltrated in $1.5 \%$ uranyl acetate-methanol solution at $-90^{\circ} \mathrm{C}$ for $30 \mathrm{hr}$. They were then embedded in Lowicryl HM-20 (EMS) and polymerized with ultraviolet light for $60 \mathrm{hr}$ at $0^{\circ} \mathrm{C}$. Ultrathin sections $(70-80 \mathrm{~nm})$ were mounted on Formvar-coated, single-slot nickel grids and processed for postembedding immunogold labeling. Sections were incubated in rabbit NR1 polyclonal antibody (1:100-1:500; Chemicon) at room temperature, rinsed in TBST (Tris-buffered saline, Tween 20), and incubated in goat antirabbit Fab fragments coupled to $15 \mathrm{~nm}$ gold particles (Biocell, Cardiff, UK). Grids were lightly stained with uranyl acetate and lead citrate and examined in a Philips CM120 electron microscope at $80 \mathrm{kV}$. Electron micrographs were taken at $20,000 \times$ using a $2 \mathrm{~K} \times 2 \mathrm{~K}$ CCD camera (Gatan Inc., Pleasanton, CA) attached to the microscope and processed using Digital Micrograph Software (Gatan Inc.).

The method used to fix and stain the tissue preserves membrane structure without compromising epitopes (Golshani et al., 2001). The immunogold staining was specific because glial cells did not label with any gold particles and $<1 \%$ of gold particles localized to mitochondria.

Data analysis. Quantification of immunocytochemistry and colocalization during live imaging was performed as detailed previously (Washbourne et al., 2002b) using Simple PCI and Image-Pro Plus software. Quantification of transport packet velocities was determined by measuring the time from the start to the end of a unidirectional motion to give the mean velocity. Clusters were considered mobile when they per- formed a unidirectional movement of $>2 \mu \mathrm{m}$ across at least three successive images. For decay of transferrin fluorescent signal, the average of 50 background-subtracted cluster intensities was plotted over time, and the $t_{1 / 2}$ was calculated from the exponential decay curve. To determine the clathrin-CFP/anti-GFP-Fab-Alexa-568 ratio of individual clusters, intensity ratios were averaged from three separate images at which an individual cluster was determined to be either immobile or mobile, i.e., in the preceding and following frames, the cluster was either colocalized or not. For quantification of immunogold labeling, gold particles were considered associated with membranes when situated $<20 \mathrm{~nm}$ from a membrane. Images were analyzed using Simple PCI and Image-Pro (Media Cybernetics, Silver Spring, MD) and processed using Adobe Photoshop. Statistics were analyzed in Excel using a two-tailed Student's $t$ test.

\section{Results}

\section{Surface labeling of endogenous NMDARs}

To examine the mechanism of trafficking of NMDAR transport packets, we first determined whether NMDARs are primarily intracellular or expressed on the surface of neurons before synapse formation. To this end, we performed surface staining for NMDARs on 3-4 DIV visual cortical neurons, an age before most synapses have formed in these cultures (Washbourne et al., 2002b). Living neurons were incubated with a directly fluorescently labeled primary antibody to the $\mathrm{N}$ terminus of NR1 for 30 $\min$ at $37^{\circ} \mathrm{C}$. This primary antibody to NR1 (R1JHL) is specific for NR1 subunits (Luo et al., 1997) and colocalizes with NR2 subunits at synapses in 8 DIV cortical cultures (supplemental Fig. 2; available at www.jneurosci.org as supplemental material). Endogenous NMDARs labeled in living neurons were clearly found in numerous clusters along the dendrites (Fig. 1C), indicating that NMDARs are expressed on the surface of living visual cortical neurons before synapse formation. Surface-labeled NMDARs were distributed at a density of $3.47 \pm 0.09$ clusters per $20 \mu \mathrm{m}$ dendrite. This may be an underestimate of the true density of NMDAR clusters on the neuronal surface because the signal from the directly labeled antibody staining was relatively weak.

To compare the distribution of surface versus intracellular NMDAR clusters, we directly conjugated the NR1 antibody to separate fluorophores and incubated neurons with them sequentially under nonpermeabilizing and then permeabilizing conditions. First, endogenous NMDARs in 4 DIV neurons were surface-labeled with NR1-Alexa- 488 at $4^{\circ} \mathrm{C}$ for $10 \mathrm{~min}$ (Fig. $1 \mathrm{~B}$, top panels). Labeling was performed at $4^{\circ} \mathrm{C}$ to prevent endocytosis of surface-labeled receptors. After fixation and permeabilization, NR1-Alexa-568 was used to detect intracellular NR1 (Fig. $1 B$, top panels). This method allowed simultaneous detection of extracellular and intracellular pools because the initial surface labeling of NR1 is saturating; nonpermeabilized neurons first labeled with NR1-Alexa- 488 at $4^{\circ} \mathrm{C}$ for $10 \mathrm{~min}$, and then subsequently labeled with NR1-Alexa-568 at $4^{\circ} \mathrm{C}$ for $10 \mathrm{~min}$, did not show detectable Alexa-568 signal (Fig. $1 \mathrm{~B}$, bottom panels).

Surprisingly, we found that many clusters of NMDARs contained both surface-exposed and intracellular receptor subunits. Most of the surface-labeled NMDARs $(89.3 \pm 0.6 \% ; n=10$ cells $)$ were colocalized with intracellular receptors. The total number of surface plus intracellular clusters observed in these neurons was $4.54 \pm 0.09$ per $20 \mu \mathrm{m}$ dendrite, a density comparable to that reported previously for total NR1 clusters in cortical neurons at this age (Washbourne et al., 2002b). Of these, $\sim 25.3 \pm 1.6 \%$ clusters had no surface component. Furthermore, the intensities of internal and surface pools in each cluster were not correlated $(r=0.03 \pm 0.02)$, implying that the ratio of the surface to intracellular pool of NMDARs in each cluster is highly variable. These results suggest that NMDARs are present in dendrites of young 


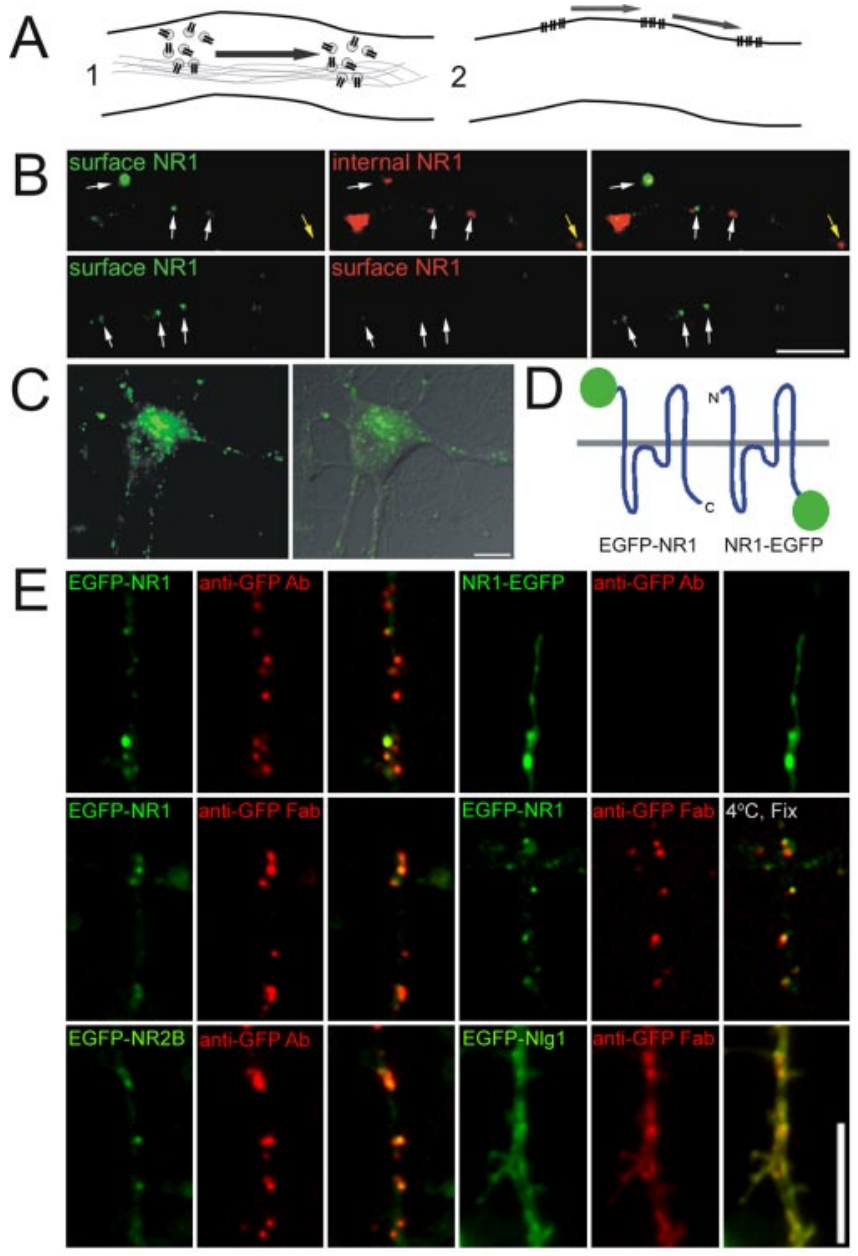

Figure 1. Surface exposure of NMDAR subunits. A, Two current models for NMDAR trafficking in dendrites: (1) transport of NMDARs intracellularly in vesicles along microtubules and (2) lateral diffusion of receptors in the plasma membrane. $B$, Surface labeling of endogenous NR1 ( $g r e e n$ ) in living 4 DIV neurons followed by staining of internal endogenous NR1 clusters (internal NR1, red) after fixation and permeabilization. Some internal clusters are not colocalized with surface NR1 (yellow arrow); however, most surface clusters are colocalized with internal clusters. Scale bar, $10 \mu \mathrm{m}$. Double application of the same antibody with different chromophores demonstrates that the first surface incubation completely saturates all available epitopes for antibody binding (surface NR1, red; bottom panels). C, Fluorescence image of surface-labeled endogenous NR1 in a living cortical neuron at 4 DIV. Scale bar, $10 \mu \mathrm{m}$. D, Location of GFP in NR1 fusion constructs. E, Surface labeling with GFP antibodies (anti-GFP Ab, red) or anti-GFP Fab fragments (anti-GFP Fab, red) of 3-4 DIV neurons transfected with NR1-EGFP, EGFP-NR1, EGFP-NR2B, and EGFP-NIg1 (green). Clustered staining was also seen when labeled with Fab fragment at $4^{\circ} \mathrm{C}$ and fixed $\left(4^{\circ} \mathrm{C}\right.$, Fix). Scale bar, $5 \mu \mathrm{m}$.

cortical neurons before synapse formation in clusters that contain both surface and underlying intracellular receptors.

\section{Surface labeling of EGFP-tagged NMDARs}

Because the staining intensity of surface-labeled endogenous NMDARs was relatively low, this approach could not be used for time-lapse imaging because of the long integration times required to capture enough signal for a single image with reasonable resolution. Therefore, we used an alternate approach for the rest of this project: neurons were transfected with EGFPNMDAR constructs, and the extracellular GFP fused to the N terminus of these receptors was labeled with high-affinity whole antibody or Fab fragments in living neurons. The 4 DIV cortical neurons were first transfected with one of several EGFP fusion constructs for NMDAR subunits and neuroligin 1 (NR1, NR2B, and Nlg1); neuroligin was included as a positive control because it is located primarily on the surface of neurons (Scheiffele et al., 2000). Recombinant protein in neurons transfected with these constructs is well intermixed with endogenous protein, and there is little to no overexpression of the recombinant protein in dendrites within 14-30 hr after transfection (Washbourne et al., 2002b) (supplemental Fig. 3; available at www.jneurosci.org as supplemental material). Immunostaining of live neurons transfected with constructs encoding extracellular GFP tags with an antibody to GFP labeled only surface receptors (Fig. 1E) (Mammen et al., 1997; Luo et al., 2002).

Live imaging of transfected neurons showed clear labeling with the GFP antibody (Fig. $1 E$ ) similar to that observed for live staining with antibodies to endogenous NR1 but at a higher intensity. We call these clusters "surface-labeled," although their subcellular localization after labeling and during subsequent imaging is unclear (they could remain on the surface or be endocytosed). Approximately $90 \%$ of EGFP-NR1 clusters were surfacelabeled during the 20 min protocol. Thus, most of the NMDAR transport packets in cortical neurons were present on the membrane surface at some point during any given $10 \mathrm{~min}$ period in young cortical neurons. This surface labeling was specific because nontransfected neurons and neurons transfected with NR1EGFP (intracellular EGFP) (Fig. 1D) did not show surface staining (Fig. $1 E$ ).

Because antibodies can induce clustering of diffuse surfaceexpressed recombinant glutamate receptors when applied to living neurons (Mammen et al., 1997), we next surface-stained transfected neurons with fluorescently labeled anti-GFP Fab fragments. This produced a staining pattern of surface NMDARs identical to that for the full anti-GFP IgG and secondary antibody (Fig. 1E), as well as for endogenous NR1 subunits. The densities of surface clusters were not significantly different between Fab fragment and whole antibody-labeled surface clusters (4.34 \pm 0.27 and $4.86 \pm 0.42$ clusters per $20 \mu \mathrm{m}$ dendrite, respectively) but were somewhat higher than endogenous receptors (3.47 \pm 0.09 ), probably as a result of detection levels. Although it is also possible that receptor clusters can be formed by endocytosis, labeling with $\mathrm{Fab}$ fragment at $4^{\circ} \mathrm{C}$ (i.e., in the absence of endocytosis) and subsequent fixation resulted in a pattern of staining identical to that found at $37^{\circ} \mathrm{C}$ (Fig. $1 \mathrm{E}, 4^{\circ} \mathrm{C}$, Fix). These results strongly support the interpretation that a proportion of NMDARs are present in clusters on the surface of young neurons before synapse formation.

As expected, the signal from surface-labeled receptors colocalized with clusters of EGFP fluorescence (Fig. $1 E$ ); however, the relative intensities of EGFP and surface label in each cluster were not correlated (EGFP-NR2B, $r=0.059, n=169$; EGFP-NR1 Fab, $r=-0.074, n=140)$, similar to our results for the internal and surface labeling of endogenous NMDARs. Thus, NMDAR clusters are heterogeneous in the proportion of GFP-fusion protein that is exposed at the cell surface. In contrast, when we analyzed the fluorescence intensities of Fab fragment-labeled EGFP-Nlg1, there was a clear correlation between the intensity of surface-label and GFP fluorescence ( $r=0.83, n=142$ ) (Fig. 3D). Because predominantly surface-expressed neuroligin 1 is almost completely accessible to antibody, it is possible that a proportion of NMDARs in a single cluster may be present in an intracellular pool, which is not immediately accessible to the antibody. This result is consistent with the observation that endogenous NMDAR clusters contain both surface-exposed and intracellular NR1 subunits (Fig. $1 B$ ).

Although there are few synapses on these young 4 DIV visual 
cortical neurons, we next tested whether surface labeling of glutamate receptors preferentially labeled synaptic receptor clusters. EGFP-NR1-transfected cells were surface-labeled and then fixed and immunostained for synapsin. Most of the surface-labeled NR1 was not colocalized with presynaptic terminals at this age (4 DIV; data not shown); only $21.2 \pm 1.9 \%$ of surface-labeled NR1 clusters were colocalized with synapsin ( $n=10$ neurons). In contrast, and in keeping with our previous findings (Washbourne et al., 2002b), most of the surface-exposed clusters of NR1 were colocalized with NR2B $(83.5 \pm 2.85 \% ; n=9$ neurons $)$, suggesting that these clusters contain assembled NMDARs. Also consistent with our previous report (Washbourne et al., 2002b), GluR1 was colocalized with $67.6 \pm 5.9 \%$ of surface-labeled NR1 clusters ( $n=10$ neurons). Thus, glutamate receptors are present at the surface of dendrites of young cortical neurons in clusters before insertion at synapses.

\section{Transport of surface-labeled receptors}

Because NMDAR transport packets are dynamically trafficked along microtubules in dendrites of young cortical neurons (Washbourne et al., 2002b), we next determined whether the surface-labeled clusters of NMDAR subunits were mobile. Using time-lapse imaging, we found that both EGFP-fused receptors and the surface antibody label moved together along neuronal dendrites (supplementary movie 1; available at www.jneurosci.org as supplemental material) (Fig. 2A). Surface-labeled NMDAR clusters traveled at between $8.50 \pm 1.8 \mu \mathrm{m} / \mathrm{min}$ (EGFPNR1) and $8.82 \pm 1.52 \mu \mathrm{m} / \mathrm{min}$ (EGFP-NR2B) (Fig. $2 B$ ). The velocity of movement for EGFP-NR1 was not significantly different when visualized with antibodies or Fab fragments $(7.48 \pm$ 0.98 and $8.50 \pm 1.8 \mu \mathrm{m} / \mathrm{min}$, respectively). These velocities differ from our previously characterized velocity of $\sim 4 \mu \mathrm{m} / \mathrm{min}$ for NR1 (Washbourne et al., 2002b). Because surface-labeled clusters are much easier to resolve than EGFP-NR1 clusters, it is possible that surface staining allows detection of additional, and faster, mobile clusters. On average, between 13 and 17\% of surface-labeled clusters (Fig. 2C) were mobile during a 5 min imaging period. Thus, NMDAR clusters are found at the surface of dendrites of young cortical neurons and are mobile.

\section{Endocytosis of surface-labeled NR1}

Although a significant proportion of surface-labeled NMDARs are mobile, their mechanism of transport is unclear. These surface-labeled NMDAR clusters could be either transported as clusters in the plasma membrane or endocytosed and then trafficked intracellularly in vesicles. Because $~ 20 \%$ of NMDARs undergo endocytosis in 7 DIV hippocampal neurons (Roche et al., 2001), we next determined what proportion of the nonsynaptic surface-labeled NMDARs are endocytosed in younger cortical neurons. First, to determine whether endogenous NMDARs are actively endocytosed, we performed reversible biotinylation of surface proteins (Ehlers, 2000) in our cultures. Surface proteins in 4 DIV cortical neurons were biotinylated (Fig. $3 A$ ) and then stripped of biotin by reduction of an incorporated disulphide bond after incubation periods from 0 to $30 \mathrm{~min}$. More than $50 \%$ of biotinylated surface NR1 was endocytosed after only 5 min of incubation at $37^{\circ} \mathrm{C}$ (Fig. $\left.3 B\right)(n=4$ experiments); however, the amount of internalized NR1-biotin decreased at 10 and $30 \mathrm{~min}$. These kinetics are in stark contrast to biotinylated neuroligin, which is present primarily on the neuronal surface; neuroligin is endocytosed at a much slower rate ( $n=3$ experiments). Because this experiment is conducted in the presence of protease inhibitors, the reduction in endocytosed NR1 after 10 and $30 \mathrm{~min}$ is
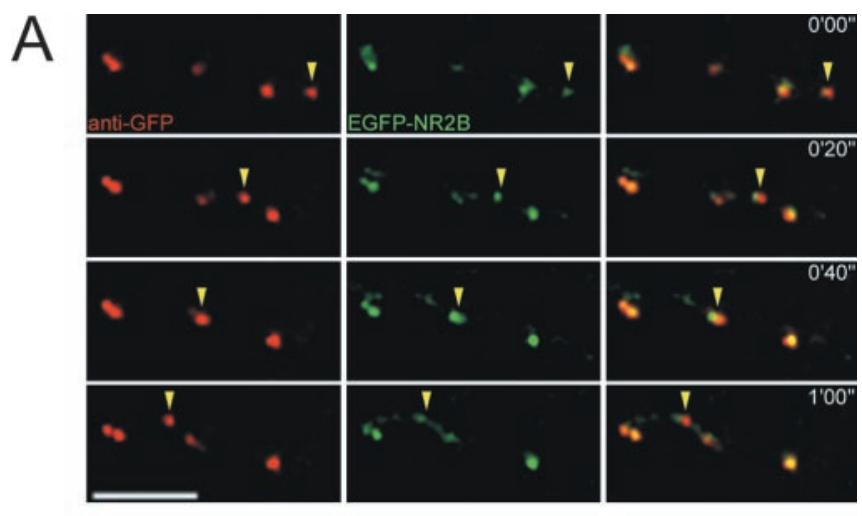

\section{$\mathrm{B}$}
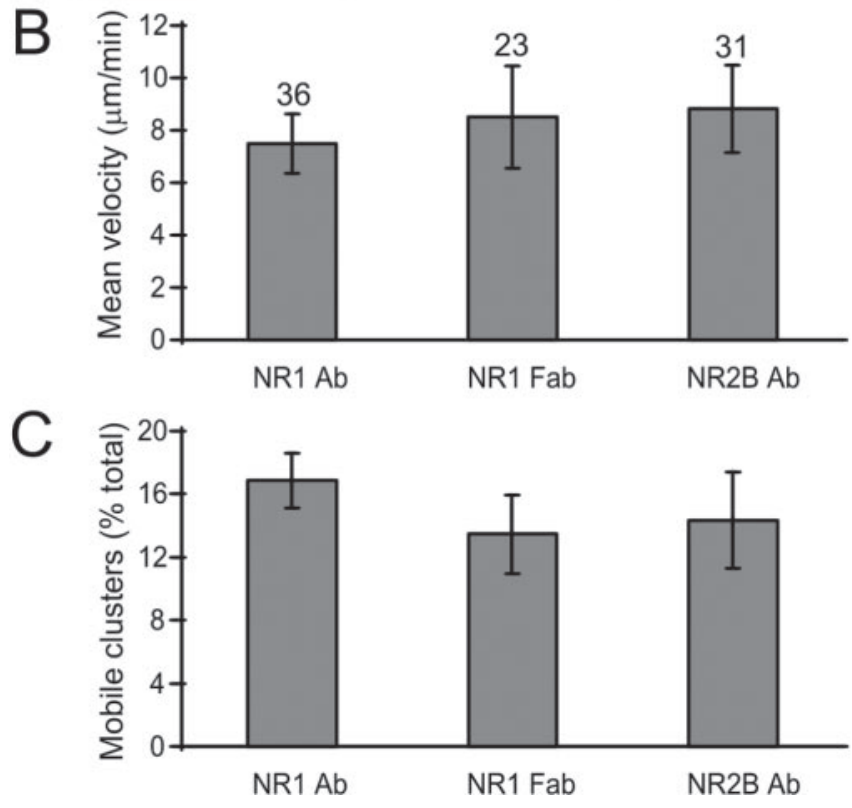

Figure 2. Dynamics of surface-exposed glutamate receptors. $A$, Movement of an EGFP-NR2B cluster (arrows) seen with both GFP fluorescence (green) and surface staining with anti-GFP antibodies (red). Images for each wavelength were acquired sequentially, causing imperfect overlap between red and green for rapidly moving clusters. Scale bar, $10 \mu \mathrm{m}$. B, Comparison of mean velocities of receptor movement revealed no significant differences between NR1 and NR2B when surface-stained ( $p>0.2$ ). Also, the mean velocities of surface-labeled NR1 clusters are not different with antibody $(\mathrm{Ab})$ or Fab fragment (Fab). Numbers above bars indicate numbers of clusters analyzed. C, The average number of mobile surface-labeled clusters observed for the NMDA receptor subunits NR1 and NR2B during any given imaging period. Again, no difference was observed between antibodies to GFP (Ab) and Fab fragments (Fab). Numbers above bars indicate numbers of clusters analyzed.

probably not caused by lysosomal degradation but suggests that NR1 may be re-exocytosed after having been endocytosed.

Surface-labeled recombinant EGFP-NR1 similarly underwent a significant amount of endocytosis. EGFP-NR1-transfected cells were labeled with Fab fragment for 10 and $60 \mathrm{~min}$. Similar to labeling using whole antibodies combined with secondary antibodies (see text above), 10 min labeling showed no correlation between the GFP and anti-GFP fluorescence intensities (Fig. 3C, top panel, D). Also, staining with $\mathrm{Fab}$ at $4^{\circ} \mathrm{C}$ and subsequent fixation gave rise to uncorrelated fluorescence intensities (average correlation $r=0.14 \pm 0.07 ; n=5$ cells); however, when the Fab fragment was incubated with transfected neurons for $1 \mathrm{hr}$ at $37^{\circ} \mathrm{C}$, the intensities became more correlated (average correlation $r=0.49 \pm 0.11$ ) (Fig. 3C, bottom panel, $D$ ). This effect is not caused by a gradual increase in binding of Fab fragment to 
surface-exposed receptors, because the same assay performed on neurons at $7 \mathrm{DIV}$ [an age at which there are twice as many synapses (Washbourne et al., 2002b) and a reduction in endocytosis (Roche et al., 2001)] does not show such a large difference between loading for 10 and $60 \mathrm{~min}$ (Fig. 3D). This increase in average correlation is also not caused by exocytosis of additional NMDARs without endocytosis, because after the $1 \mathrm{hr}$ incubation it is possible to perform 10 min labeling using a polyclonal antibody to GFP and secondary antibody that remains uncorrelated $(r=$ $-0.151 ; n=3$ cells). Because predominantly surface-expressed neuroligin 1 is almost completely accessible to antibody (Fig. 3D), this result is consistent with our interpretation from endogenous surface versus intracellular staining (Fig. $1 B$ ) that a proportion of NMDARs in a single cluster may be present in an intracellular pool, which is not immediately accessible to antibody.

\section{Recycling of NMDARs}

To explore the possibility that endocytosed NMDARs are recycled to the neuronal surface during trafficking, we used a pulse-chase assay for receptor cycling. EGFP-NR1-transfected neurons were first labeled with anti-GFP antibody at $4^{\circ} \mathrm{C}$, and then receptors were allowed to internalize for various times at $37^{\circ} \mathrm{C}$. Antibody remaining on the neuronal surface was stripped with an acid wash. Then, the living neurons were surface-labeled with secondary antibody at $37^{\circ} \mathrm{C}$ and imaged live (Fig. 3E). Using this protocol, NMDARs were labeled with secondary antibody only if they had undergone endocytosis and exocytosis between the primary and secondary antibody incubations. When NMDARs were prevented from undergoing endocytosis by incubation at $4^{\circ} \mathrm{C}$, most of the labeling of the surface receptors was abolished (Fig. $3 E$ ) ( 0 min; $n=18$ cells); however, when surfacelabeled NMDARs were allowed to undergo cycling by incubation at $37^{\circ} \mathrm{C}$, labeling was preserved (Fig. $3 E$ ) (5-30 min; $n=18$ cells) and labeled NMDARs were mobile (data not shown). Counts of the numbers of clusters of surface-labeled receptor subunits showed the same trend as seen for the endogenous biotinylated receptors (Fig. $3 F$ ). The density of clusters present after 5 min of cycling was $\sim 50 \%$ of the normal cluster density $(4.86 \pm 0.42$ clusters per $20 \mu \mathrm{m}$ dendrite; see above). In contrast, few clusters of recycling neuroligin were present (Fig. $3 F)(n=12$ cells). Finally, to address whether the cycling of NMDARs is dependent on receptor activation or activity, we performed the same pulsechase experiment on cells treated with NBQX $(10 \mu \mathrm{M})$ and APV $(50 \mu \mathrm{M})$ or tetrodotoxin $(1 \mu \mathrm{M})$ for $18 \mathrm{hr}$ before imaging. These treatments had no effect on the number of clusters seen after a 5 min chase at $37^{\circ} \mathrm{C}$ (data not shown). In conclusion, these results suggest that a large proportion of surface NMDARs are in fact

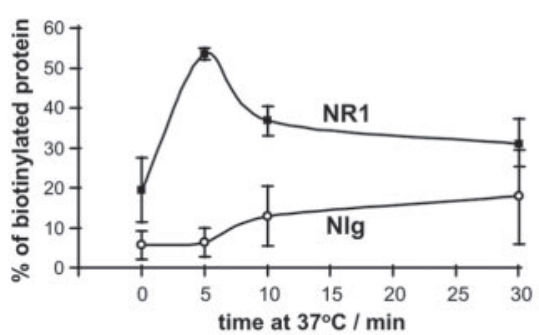

\section{D}

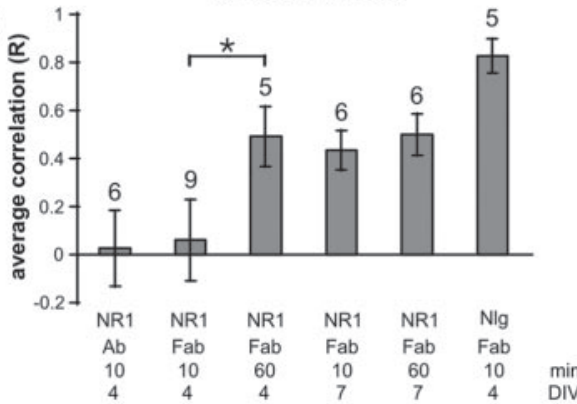

$\mathrm{F}$

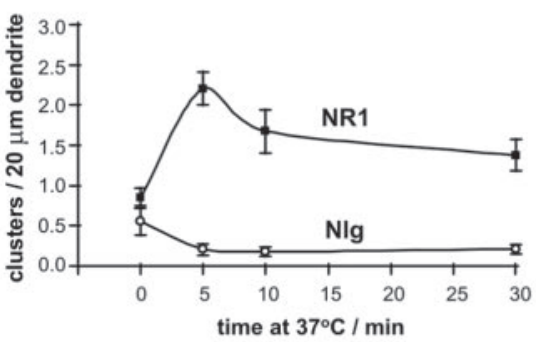

Figure 3. Endocytosis and recycling of NMDARs. $A$, Biotinylation of endogenous NMDARs on 4 DIV cortical neurons. After biotinylation, surface biotin was removed by reduction with glutathione following an incubation at $37^{\circ} \mathrm{C}$ for the times indicated.

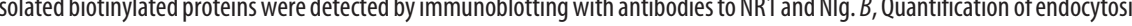
as a percentage of total biotinylated protein over time (NR1, $n=4$ experiments; Nlg, $n=3$ experiments). C, Comparison of

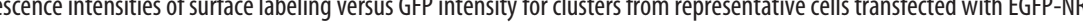
antibody (Ab) and Fab fragment (Fab) intensities when applied for 10 or 60 min to 4 and 7 DIV transfected neurons. Numbers . acid wash at $4^{\circ} \mathrm{C}$. Internalized receptors were allowed to recycle to the surface at $37^{\circ} \mathrm{C}$ for labeling with secondary antibody (red) Scale bar, $5 \mu \mathrm{m}$. F, Cluster density of surface-labeled EGFP-NR1 (NR1, $n=18$ neurons for each condition) and EGFP-Nlg1 (Nlg, $n=10$ neurons) after acid stripping following various times for internalization.

internalized in a ligand-independent manner and subsequently exocytosed. This process takes $<5 \mathrm{~min}$ to occur in cells that are being subjected to temperature oscillations.

\section{Internalized NMDAR transport packets may be endosomes trafficked with SAP102}

It has been proposed recently that NMDAR trafficking and exocytosis may be performed by the exocyst complex and that this interaction is mediated by the scaffolding protein SAP102 (Sans et al., 2003). Furthermore, we have shown previously that PSD95, another scaffolding protein, is not transported with NMDARs in young cortical neurons (Washbourne et al., 2002b). To address the possibility that SAP102 is trafficked together with endocytosed NMDARs, we surface-labeled EGFP-NR1, fixed the neurons, and performed immunocytochemistry (Fig. $4 A$, left panels); $62.9 \pm 3.1 \%$ of surface-labeled EGFP-NR1 colocalized with SAP102 ( $n=13$ cells). In addition, after a 5 min pulse-chase incubation at $37^{\circ} \mathrm{C}$ and acid stripping as described above, $80.7 \pm$ $3.1 \%$ of EGFP-NR1 colocalized with SAP102 ( $n=13$ cells) (Fig. $4 A$, right panels). These data strongly suggest an association spe- 


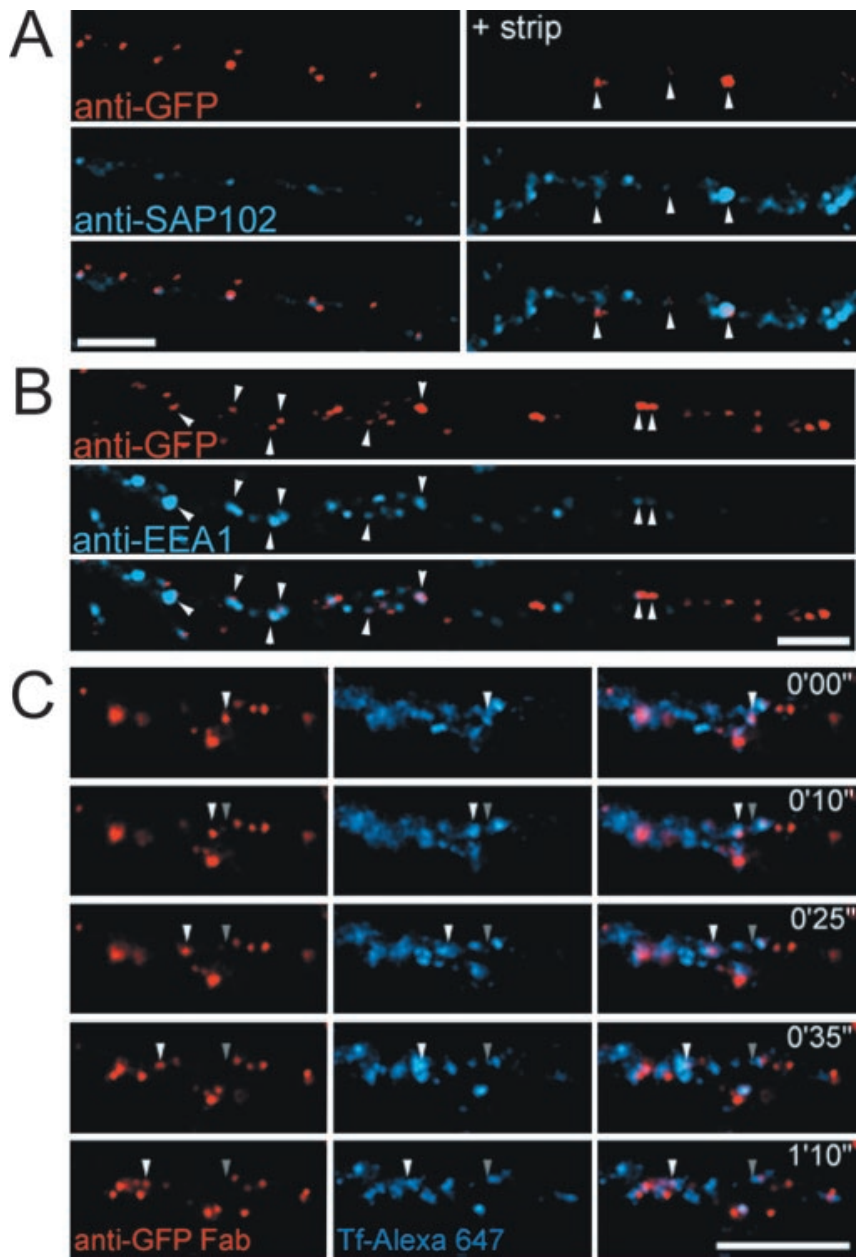

Figure 4. Internalized NMDAR clusters associate with SAP102, EEA1, and transferrin. $A$, Immunocytochemistry for SAP102 (blue) after surface labeling of EGFP-NR1-transfected neurons (red, left) and surface-labeled and stripped neurons (+ strip, red, right). Arrowheads show colocalization of internalized EGFP-NR1 with SAP102. Scale bar, $5 \mu \mathrm{m}$. B, Immunocytochemistry for EEA1 (blue) after surface labeling of EGFP-NR1-transfected neurons (red). Arrowheads show colocalization of internalized EGFP-NR1 with EEA1. Scale bar, $5 \mu \mathrm{m}$. C, Simultaneous application of anti-GFP Fab fragments (red) and labeled transferrin to an EGFP-NR1-transfected neuron. A mobile surface-labeled NR1 cluster (white arrows) colocalized with transferrin. Gray arrows denote original location. Time is in minutes and seconds. Scale bar, $10 \mu \mathrm{m}$. D, Analysis of all surface-labeled NR1 clusters showed that $50 \%$ of mobile NMDAR clusters were also labeled with transferrin ( $n=5$ neurons).

cifically of internalized NMDARs with this scaffolding protein during trafficking.

To address the identity of internalized NMDAR clusters, we also immunostained surface-labeled transfected neurons for the early endosomal marker EEA1 (Ehlers, 2000). At this age, EEA1 immunoreactivity was distributed in a proximal to distal gradient in dendrites (Fig. $4 B$, left to right), suggesting either that early endosomes are not yet present in distal dendrites or that EEA1 is present in a strong gradient throughout the dendritic endosomal compartment. Overall colocalization of NR1 with EEA1 was only $67.4 \pm 4.1 \%(n=12$ cells $)$; however, in regions of strong EEA1 immunoreactivity, colocalization was $82.3 \pm 3.1 \%$ ( $n=12$ cells), suggesting that NMDAR clusters do associate with the early endosomal compartment.

To further investigate the dynamics of endocytosis, labeled transferrin (Tf) was applied to EGFP-NR1-transfected neurons together with anti-GFP Fab fragments. Tf is endocytosed by a clathrin-mediated mechanism (Blanpied et al., 2002). Time-lapse imaging revealed that $\mathrm{Tf}$ was internalized and transported together with surface-labeled NR1 (Fig. 4C). In fact, $50.0 \pm 18.6 \%$ of mobile surface-labeled NR1 clusters ( $n=5$ neurons) contained Tf (Fig. $4 D$ ), whereas only $19.7 \pm 8.5 \%$ of immobile NR1 clusters colocalized with Tf. Because the signal from the labeled Tf decreased rapidly over time $\left(t_{1 / 2}=4.32 \pm 1.3 \mathrm{~min} ; n=5\right.$ neurons), it is probable that endocytosed Tf is quickly released back into the extracellular medium, perhaps by rapid cycling of the NMDAR transport packets with the plasma membrane. These results suggest that a large proportion of mobile surfacelabeled NMDAR clusters were endocytosed within the 2 min labeling protocol.

\section{Dynamics of NMDAR endocytosis}

Because NMDARs have been shown previously to be endocytosed by a clathrin-dependent mechanism (Roche et al., 2001), we further addressed the dynamics and time course of endocytosis of NMDARs by cotransfecting a fluorescently tagged clathrin construct into 3-4 DIV cortical neurons together with EGFPNR1. Clathrin-CFP was distributed along dendrites and appeared and disappeared at discrete locations (hotspots) (Fig. 5A). This behavior of clathrin-CFP correlates with sites of clathrinmediated endocytosis and showed similar kinetics in our young cortical neurons as reported recently in more mature hippocampal cultures (Blanpied et al., 2002) (Fig. 5B). Although moving clusters of Fab fragment-labeled NR1 did not colocalize with clathrin-CFP (Fig. 5C-E), immobile clusters of Fab fragmentlabeled NR1 often colocalized with clathrin hotspots (Fig. 5C-E). In fact, surface-labeled NMDAR transport packets moved from clathrin hotspot to hotspot in swift succession (up to six times in one imaging period), with an average period between clathrin hotspots of $54.3 \pm 7.9 \mathrm{sec}(n=11$ mobile clusters $)$. When the intensities of clathrin-CFP (434 nm) to Fab-labeled NR1 (568 $\mathrm{nm}$ ) were measured for single clusters during mobile and paused periods, the intensity ratio was found to be $60 \%$ lower on average when individual clusters were mobile (Fig. 5D) $(n=20)$, suggesting that clathrin-CFP is preferentially associated with immobile NR1. This effect was found for both NR1 and NR2B. The colocalization of clathrin with immobile NR1 clusters suggests that surface-exposed NR1 is endocytosed by a clathrin-mediated mechanism only when immobile and that rounds of endocytosis could occur with a frequency as fast as one per minute (if endocytosis occurs at every clathrin hotspot).

\section{Exocytosis of NMDAR transport packets occurs via a SNAP} receptor-dependent mechanism

Because the insertion of AMPA receptors (AMPARs) into the plasma membrane is dependent on an interaction with NSF protein and $\alpha / \beta$-SNAPs (Osten et al., 1998; Noel et al., 1999), we next tested whether NMDARs are also inserted into the plasma membrane by a SNAP receptor (SNARE)-mediated mechanism (Sollner et al., 1993). Vesicular fusion necessary for exocytosis can be blocked with BoNT types A and E, which specifically cleave SNAP-25 (Fig. 6A) (Schiavo et al., 1993). Although BoNT/A has been shown to cleave the ubiquitous SNAP-25 homolog SNAP23 , it does this only at very high concentrations (Vaidyanathan et al., 1999). In fact, with our cotransfection protocol we were unable to detect any cleavage product of SNAP-23 by BoNT/A, whereas BoNT/E was able to cleave SNAP-23 to the same extent as SNAP-25 (Fig. 6A).

Cortical neurons were cotransfected with ECFP-NR1 and a bicistronic expression vector containing the coding sequences of the light-chain of either BoNT/A or BoNT/E and GFP (BoNT/A- 
IRES-GFP and BoNT/E-IRES-GFP). Transfected neurons were imaged once their NMDARs had been surface-labeled with anti-GFP antibodies. Clearly, the average number of surface clusters of ECFPNR1 was dramatically reduced in neurons cotransfected with BoNT/E (Fig. 6B). In fact, there were 3.5-fold fewer surface clusters when BoNT/E was expressed (Fig. 6C) ( $n=10$ neurons), and the fluorescence intensity of the few remaining surface clusters was reduced by a factor of 3 (Fig. 6D). There was no such reduction in the presence of BoNT/A, suggesting that it is the cleavage of SNAP-23 by BoNT/E, and not the cleavage of SNAP-25 (which both toxins cleave), that blocks exocytosis of NMDAR transport packets. Despite the large effect of BoNT/E on surface NMDAR expression, the total pool of NMDARs was unaffected in BoNT/E-transfected neurons; the average intensity of ECFP-NR1 was not different in the presence of BoNT/ E-IRES-GFP as compared with GFP alone $(1062.5 \pm 152.9$ and $990.7 \pm 126.2$ a.u.; $n=5$ cells). These data demonstrate that the vesicular exocytosis of NMDAR transport packets is dependent on SNAREmediated vesicle fusion, specifically by the ubiquitous target membrane-associatedSNARE, SNAP-23. Our results also suggest that NMDARs must undergo exocytosis to replenish the surface receptor population over time.

\section{Ultrastructural localization of NR1}

To determine the identity of the NMDAR transport organelles, EM was used. First, immuno-EM was performed on transfected neurons from 4 DIV cultures that had been surface-labeled with an antibody to GFP and a $15 \mathrm{~nm}$ gold-labeled secondary antibody. After identification of a transfected neuron by imaging, the coverslip was processed for EM. Although very few particles of gold were present on the transfected neurons analyzed (because of loss of gold particles during processing), the labeling that was seen is likely to be specific because gold particles were never present on nontransfected cells. On three transfected neurons analyzed, a total of nine particles of gold were identified. Three of these gold particles were present at the plasma membrane, and the rest were found within the dendrites of the neurons (Fig. 7A). Despite the fact that imaging cultured neurons before processing compromises cellular ultrastructure, the surface-labeled gold had clearly been internalized and was closely associated with internal membranes of tubulovesicular structures (Fig. 7A).

To determine whether intracellular membrane localization and tubulovesicular transport of NMDARs is apparent also in vivo, we analyzed sections of P2 mouse cerebral cortex that had been immunostained for NR1 with $15 \mathrm{~nm}$ gold particles. Although very few synapses are present in cortex at P2, NR1 immunogold was detected at 7 of 15 immature excitatory synapses (Fig. $7 B)$. In addition, using the same protocol on P32 mice, NR1 was readily detected at $\sim 40 \%$ of synapses. At P2, immunogold particles clearly decorated membranes in the soma and dendrites of cortical neurons (Fig. $7 C-F)$. Most of the gold particles $(87 \%$; $n=140$ ) were localized to vesicles (Fig. $7 D-F)$, tubulovesicular structures (Fig. 7C), and the plasma membrane (Fig. 7E). Most $(60.7 \%)$ of the gold particles were found within $20 \mathrm{~nm}$ of vesicle membranes, whereas 12.9 and $13.6 \%$ of the gold particles were found at tubulovesicular structures and the plasma membrane, respectively (Fig. $7 G$ ). Only $12.2 \%$ of gold particles could not be assigned to distinct membranous structures.

The average size of NR1-labeled vesicles was $243 \mathrm{~nm}$ but ranged from 45 to $600 \mathrm{~nm}$ (Fig. $7 \mathrm{H}$ ). Thus, the average size of NMDAR-containing vesicular structures in vivo is different from the $50 \mathrm{~nm}$ KIF-17 immunopurified vesicles previously reported to contain NR2B (Setou et al., 2000) but is similar to the SAP102containing vesicles reported in juvenile hippocampus (Sans et al., 2003). Although it is difficult to compare EM of immunopurified organelles with EM conducted on intact tissue, it is possible that the $50 \mathrm{~nm}$ vesicles represent a subpopulation of NMDAR transport packets, because 4 of the 32 immunogold-decorated vesicles were within this size range (Fig. $7 H$ ). It is unlikely, however, that 

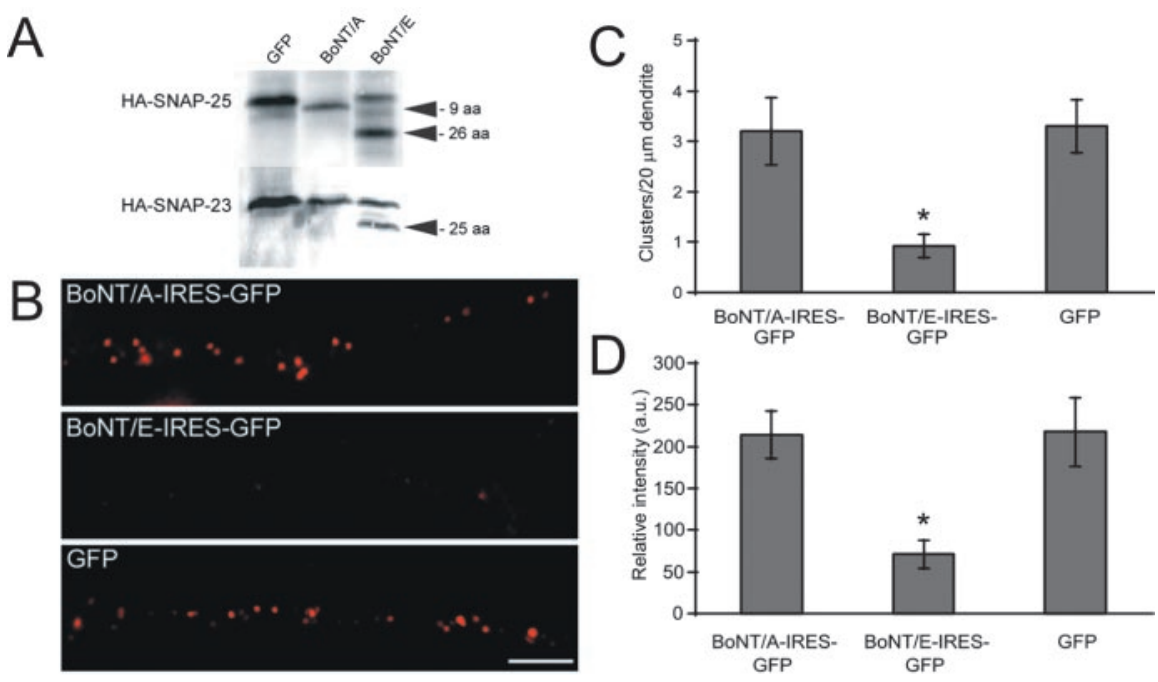

Figure 6. SNAP-23-mediated exocytosis of NMDARs. A, Cleavage of HA-tagged SNAP-25 and SNAP-23 by BoNT/A and BoNT/E when transfected into $\mathrm{CHO}$ cells. BoNT/E was effective in increasing the electrophoretic mobility of HA-SNAP-25 and HA-SNAP-23 by cleaving 26 and 25 amino acids from the C terminus, respectively. BoNT/A cleaved nine amino acids from SNAP-25 but was unable to cleave HA-SNAP-23. B, Surface labeling of NR1 (red) in 4 DIV neurons cotransfected with CFP-NR1 and the light-chains of BoNT/A and BoNT/E in an IRES-GFP vector. Segments of anti-GFP-labeled dendrites from neurons transfected with these constructs are shown. Scale bar, $5 \mu \mathrm{m}$. C, Density of anti-GFP-labeled NR1 clusters in cells cotransfected with BoNT/A or BoNT/E and GFP ( $n=10$ neurons; $p<0.002$ ). D, Intensity of anti-GFP-labeled NR1 clusters in cells cotransfected with BoNT/A or BoNT/E and GFP ( $n=10$ neurons; $\left.{ }^{*} p<0.001\right)$. a.u., Arbitrary units.

this represents the only mobile population of NMDAR transport packets, because a few of the $200 \mathrm{~nm}$ vesicles ( 3 of 32) were clearly associated with microtubules (Fig. $7 D$, arrows). This association of NMDAR transport packets with microtubules is consistent with pharmacological results suggesting that NMDARs are transported along microtubules (Washbourne et al., 2002b).

NR1-labeled vesicles were often present in close proximity to each other (Fig. $7 F$ ) and to the plasma membrane (Fig. $7 E$ ). The average number of vesicles seen within a $1 \mu \mathrm{m}$ radius of a goldlabeled vesicle was $3.1 \pm 0.5(n=26)$, and the proportion of gold-labeled vesicles present within a one-vesicle radius $(200 \mathrm{~nm})$ of the plasma membrane was $43.7 \%$. These numbers are likely to be underestimates because serial EM sections were not examined. In general, these numbers suggest that NMDAR clusters in vivo are represented by collections of vesicles that are close enough to the plasma membrane to undergo exocytosis and endocytosis between periods of intracellular transport along microtubules. In addition, the fact that most of the NR1 was associated with intracellular vesicles and not the plasma membrane suggests that exocytosis is tightly coupled to endocytosis.

\section{Discussion}

Rather than being trafficked exclusively intracellularly or within the plasma membrane (Fig. 1A), NMDAR transport packets undergo a novel form of transport punctuated by cycles of exo/ endocytosis in dendrites of young visual cortical neurons. A large proportion of NMDAR clusters are endocytosed into endosomal vesicles associated with SAP102, undergo microtubuledependent movement possibly mediated by a kinesin-like motor protein (Setou et al., 2000; Guillaud et al., 2003), pause often at clathrin hotspots, and recycle with the membrane. Because only $\sim 17 \%$ of surface-labeled NMDARs are mobile while $50 \%$ of surface-labeled receptors undergo recycling, a large proportion of these cycling receptors remain stationary at sites of exo/endocytosis. Some of these surface-labeled receptors, however, must be transported soon after being endocytosed because $50 \%$ of the mobile surfacelabeled NMDARs colocalize with fluorescently labeled transferrin. Our results are consistent with two possible models for NMDAR transport in dendrites before synapse formation: (1) periods of exo/endocytosis with intracellular transport between cycles (Fig. 8A) and/or (2) periods of exo/endocytosis with simultaneous transport of NMDAR clusters within the membrane and intracellularly between cycles (Fig. $8 B$ ).

The mechanism of cycling of NMDARs in young cortical neurons before synapse formation involves classic forms of endocytosis and exocytosis. A developmental decline in clathrin-dependent NMDAR endocytosis in hippocampal neurons has been demonstrated previously (Roche et al., 2001). We extend those results here by showing a similar phenomenon in younger cortical neurons before synaptogenesis. Surface biotinylation assays and colocalization with transferrin indicate that approximately half of the surface NMDARs on 4 DIV cortical neurons is internalized within 5 min (Figs. 3, 4). Exocytosis of NMDARs before synapse formation occurs through a SNARE-dependent, SNAP-23-mediated process (Fig. 6). Although SNAP-25 has been implicated in NMDAR trafficking and function at synapses in more mature neurons (Lan et al., 2001) (but see Washbourne et al., 2002a), cleavage of SNAP-25 alone did not block surface expression of NMDARs in young visual cortical neurons. Most importantly, acid-stripping experiments clearly demonstrate that NMDARs undergo a full cycle of exocytosis and endocytosis during transport; approximately half of the surface NMDARs are recycled during a 5 min period.

Although it is clear that approximately half of the surfacelabeled NMDARs undergo one cycle of exo/endocytosis within 5 min of surface-labeling, it is important to note that our data do not directly address whether NMDAR clusters undergo multiple cycles with the membrane during their transport. Three of our results, however, are consistent with multiple cycles for NMDAR clusters during trafficking. First, $\sim 50 \%$ of surface-labeled NMDAR clusters undergo recycling within 5 min of surface staining; this is the same number that undergoes endocytosis in the same length of time. It is highly unlikely that this large proportion of total protein is targeted for degradation after two cycles with the membrane because the neuron would require parallel rapid synthesis and insertion of such a large number of new receptors to maintain the surface pool. Second, the reduction in the amount of endocytosis of surface-labeled NMDARs at 10 and 30 min suggests that these receptors are reinserted into the membrane and not degraded by lysosomes because of the presence of protease inhibitors. Third, NMDAR clusters were observed to pause repeatedly at clathrin-containing hotspots between periods of mobility, which suggests indirectly that these clusters could undergo cycling during sequential stops at hotspots. This experiment suggests that the time course of exo/endocytic cycles (at clathrin hotspots) may be as fast as every minute, if NMDARs cycle at every clathrin hotspot (Fig. 5). 
Ultrastructure and immunocytochemistry of the NMDAR transport packets provide critical information about the nature of the transport packets and the mechanism of their trafficking within dendrites before synapse formation (Figs. 4, $7)$. Both in cultured cortical neurons and in vivo in $\mathrm{P} 2$ cortex, most of the NR1 was associated with intracellular tubulovesicular structures, and several of these were clearly associated with microtubules. Immunocytochemistry with EEA1 suggests that many of these vesicles are early endosomes that have undergone endocytosis via a clathrin-mediated mechanism (because of their association with transferrin and clathrin) (Figs. 4, 5). Furthermore, high colocalization of internalized NMDARs with SAP102 is consistent with the hypothesis that this scaffolding protein may be critical for NMDAR transport and exocytosis before synapse formation (Sans et al., 2003). Because NR1-containing vesicles are often found in clusters of three or more, mobile clusters of glutamate receptors may be composed of multiple receptorcontaining vesicles, only some of which fuse with the membrane at any given time. Consistent with this interpretation, the amount of surface and intracellular endogenous NMDARs in each NMDAR-containing cluster is highly variable and uncorrelated (Fig. 1B). Similarly, EGFP-NR1 transport packets are heterogeneous in the proportion of GFP-fusion protein that is exposed at the cell surface (Fig. 1D). Finally, because approximately half of these NMDAR-containing vesicles are within a one-vesicle radius of the plasma membrane, these vesicles are close enough to the plasma membrane to undergo rapid exocytosis and endocytosis between periods of transport. It was reported recently that NMDAR transport packets are not present in older hippocampal neurons and
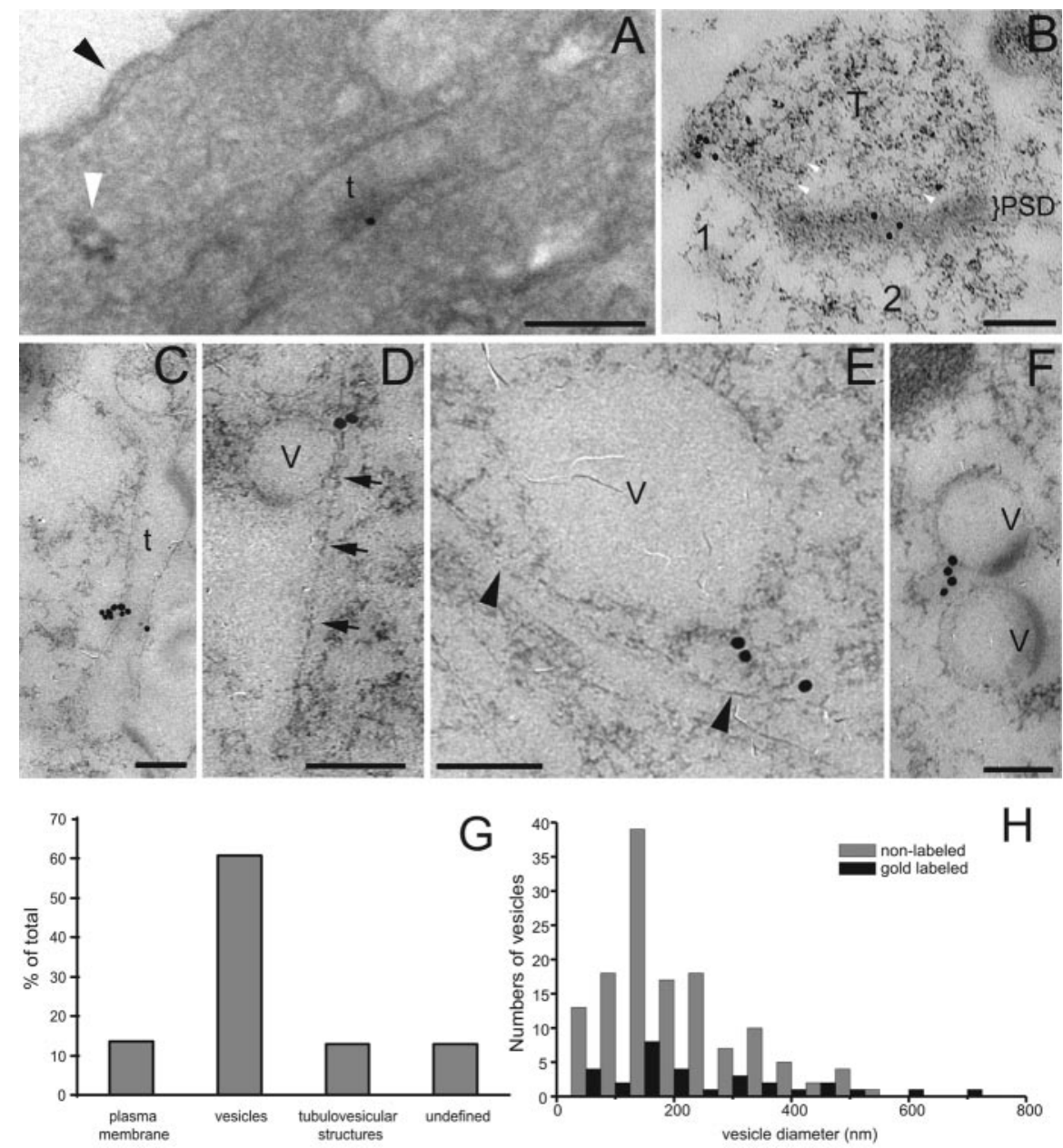

Figure 7. Ultrastructural localization of NR1 in cortical dendrites in vivo. A, Retrospective immunogold EM of a neuron transfected with EGFP-NR1 and surface-labeled with anti-GFP and $15 \mathrm{~nm}$ gold-labeled secondary antibodies. Surface-labeled gold particles (white arrow) were found on internal membranous organelles, indicating that the surface-labeled receptors were endocytosed. Note the clathrin-coated vesicle (white arrowhead) close to the plasma membrane (black arrowheads). t, Tubulovesicular structure. Scale bar, $200 \mathrm{~nm}$. B-F, Immunogold EM for NR1 in P2 mouse cortex showed localization of gold particles at postsynaptic densities ( $B, P S D)$, at vesicular membranes, and at nonsynaptic plasma membrane (black arrowheads). Note the localization of an NR1-labeled vesicle on microtubules ( $D$, black arrows). v, Vesicle; $t$, tubulovesicular structure; T, presynaptic terminal (small white arrowheads show some synaptic vesicles). Scale bars, $200 \mathrm{~nm}$. G, Quantification of the localization of all gold particles from 74 dendritic profiles. Most NR1 is localized to intracellular vesicles. The total number of gold particles examined was 140. $H$, Size distribution of gold-labeled and nonlabeled vesicles seen in the dendritic profiles. The average size was $261.7 \pm 60$ and $206.1 \pm 11.4 \mathrm{~nm}$ for gold-labeled and nonlabeled vesicles, respectively ( $n=60$ and 123). that NMDARs accumulate gradually over time at new sites of synapse formation in older cultures (Bresler et al., 2004). This may reflect either a change in the number and/or size of NMDAR transport packets over development or methodological differences between the experimental approaches.

As mentioned above, our results are consistent with two possible models for NMDAR transport before synapse formation: (1) periods of exo/endocytosis and intracellular transport between cycles (Fig. 8A) and/or (2) periods of exo/endocytosis and simultaneous transport of NMDAR clusters within the membrane and intracellularly between cycles (Fig. $8 \mathrm{~B}$ ). The third possible model, that NMDARs are transported only when in the plasma membrane, is inconsistent with our data because surfacelabeled NMDAR clusters have intracellular receptors associated with them, and NR1-positive vesicles were clearly colocalized with microtubules with EM. Consistent with the first model, we found that at least half of the mobile surface-labeled NMDAR clusters colocalize with fluorescently labeled transferrin (Fig.

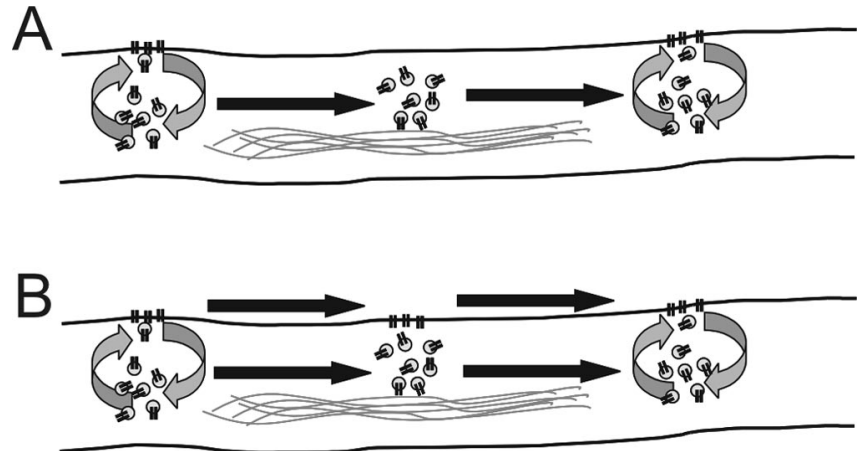

Figure 8. Proposed models for NMDAR trafficking. Illustrations of two possible models for exo/endocytic cycling and microtubule transport-based trafficking of NMDAR transport packets. $A$, Exo/endocytosis during pausing, with internal transport of NMDAR-containing vesicles along microtubules. $B$, Exo/endocytosis during pausing and transport of surface and internal pools of NMDARs together along microtubules. See Discussion for details. 
$4 C, D)$. This result implies that these clusters were endocytosed and then became mobile; it is unlikely that these mobile clusters had rapidly reinserted into the plasma, because that would lead to the loss of transferrin. Furthermore, immuno-EM shows that only $\sim 13 \%$ of NMDARs are found at the plasma membrane at a given time, suggesting that only a small fraction of the total NMDARs could be transported in the plasma membrane at this stage in development. It is also possible, however, that NMDARs are trafficked both intracellularly and within the plasma membrane between cycles of endo/exocytosis (Fig. $8 \mathrm{~B}$ ). Consistent with this model is the recently reported observation that a subpopulation of NMDARs may travel in detergent insoluble glycolipid-rich rafts at the dendritic surface, because they have been shown to cofractionate with caveolin and raft lipids (Hering et al., 2003). Interestingly, the complete dependence of NMDAR transport on microtubules (Washbourne et al. 2002a,b) implies that receptors transported within the membrane must somehow be linked to microtubules. Although the molecular links are not known, this form of trafficking may be analogous to the surface transport of NCAM while being tethered to trans-Golgi network organelles (Sytnyk et al., 2003).

Although cycling of NMDARs through the dendritic plasma membrane during their trafficking before synapse formation clearly occurs, the functional significance of this novel phenomenon is unknown. Several intriguing hypotheses can be envisioned. The first possibility is that cycling of NMDARs is an integral step in post-Golgi trafficking and sorting. A sorting step is possibly required to separate AMPARs from NMDARs during trafficking from the ER and Golgi to synapses (Washbourne et al., 2002b); this sorting step could occur through exocytosis of both AMPARs and NMDARs to the dendritic surface, followed by differential endocytosis of these receptors. A similar plasma membrane maturation step has been proposed recently for the axonal protein VAMP (vesicle-associated membrane protein), which requires a sorting step at the dendritic plasma membrane before targeting to the axon and synaptic vesicles (Sampo et al., 2003). Alternatively, NMDAR cycling before synapse formation may allow neurons to sense ambient glutamate in their environment, thereby causing the neuron to respond to nearby neurons before synapses are formed. Early nonsynaptic detection of glutamate plays a key role in several phases of development, such as neuronal migration (Komuro and Rakic, 1993; Demarque et al., 2002) and synaptogenesis, by sensing vesicular release from a nearby glutamatergic axon or nonvesicular release from neighboring neurons or glia (Young and Poo, 1983; Demarque et al., 2002). Although glutamate release is not required for synapses to form (Rao and Craig, 1997; Verhage et al., 2000; Washbourne et al., 2002a), it is possible that detection of glutamate released from neighboring cells could influence the likelihood of synapse formation and/or the location on a neuron where synapses are formed (Lin and Constantine-Paton, 1998; Maletic-Savatic et al., 1999; Wong and Wong, 2000; Lohmann et al., 2002).

In summary, our results suggest a novel model for NMDAR trafficking before synapse formation. Rather than being transported exclusively intracellularly or on the dendritic surface, NMDARs are rapidly cycled to the dendritic plasma membrane between periods of microtubule-dependent transport. Although the cellular mechanisms of this transport are defined here, its function during synapse formation, possible regulation by environmental signals, and downregulation at synaptic sites remain exciting areas for future experiments.

\section{References}

Bekkers JM, Stevens CF (1989) NMDA and non-NMDA receptors are colocalized at individual excitatory synapses in cultured rat hippocampus. Nature 341:230-233.

Blanpied TA, Scott DB, Ehlers MD (2002) Dynamics and regulation of clathrin coats at specialized endocytic zones of dendrites and spines. Neuron 36:435-449.

Bresler T, Shapira M, Boeckers T, Dresbach T, Futter M, Garner CC, Rosenblum K, Gundelfinger ED, Ziv NE (2004) Postsynaptic density assembly is fundamentally different from presynaptic active zone assembly. J Neurosci 24:1507-1520.

Carroll RC, Beattie EC, Xia H, Luscher C, Altschuler Y, Nicoll RA, Malenka RC, von Zastrow M (1999) Dynamin-dependent endocytosis of ionotropic glutamate receptors. Proc Natl Acad Sci USA 96:14112-14117.

Choquet D, Triller A (2003) The role of receptor diffusion in the organization of the postsynaptic membrane. Nat Rev Neurosci 4:251-265.

Cohen-Cory S (2002) The developing synapse: construction and modulation of synaptic structures and circuits. Science 298:770-776.

Craig AM, Banker G (1994) Neuronal polarity. Annu Rev Neurosci 17:267-310.

Demarque M, Represa A, Becq H, Khalilov I, Ben-Ari Y, Aniksztejn L (2002) Paracrine intercellular communication by a Ca- and SNAREindependent release of GABA and glutamate prior to synapse formation. Neuron 36:1051-1061.

Ehlers MD (2000) Reinsertion or degradation of AMPA receptors determined by activity-dependent endocytic sorting. Neuron 28:511-525.

Fu Z-Y, Washbourne P, Ortinski P, Vicini S (2003) Functional excitatory synapses in HEK293 cells expressing neuroligin and glutamate receptors. J Neurophysiol 90:3950-3957.

Golshani P, Liu X-B, Jones EG (2001) Differences in quantal amplitude reflect GluR4-subunit number at corticothalamic synapses on two populations of thalamic neurons. Proc Natl Acad Sci USA 98:4172-4177.

Guillaud L, Setou M, Hirokawa N (2003) KIF17 dynamics and regulation of NR2B trafficking in hippocampal neurons. J Neurosci 23:131-140.

Hering H, Lin C-C, Sheng M (2003) Lipid rafts in the maintenance of synapses, dendritic spines, and surface AMPA receptor stability. J Neurosci 23:3262-3271.

Hollmann M, Heinemann S (1994) Cloned glutamate receptors. Annu Rev Neurosci 17:31-108.

Komuro H, Rakic P (1993) Modulation of neuronal migration by NMDA receptors. Science 260:95-97.

Lan JY, Skeberdis VA, Jover T, Zheng X, Bennett MV, Zukin RS (2001) Activation of metabotropic glutamate receptor 1 accelerates NMDA receptor trafficking. J Neurosci 21:6058-6068.

Lin SY, Constantine-Paton M (1998) Suppression of sprouting: an early function of NMDA receptors in the absence of AMPA/kainate receptor activity. J Neurosci 18:3725-3737.

Lohmann C, Myhr KL, Wong RO (2002) Transmitter-evoked local calcium release stabilizes developing dendrites. Nature 418:177-181.

Luo J-H, Wang Y, Yasuda RP, Dunah AW, Wolfe BB (1997) The majority of $\mathrm{N}$-methyl-D-aspartate receptor complexes in adult rat cerebral cortex contain at least three different subunits (NR1/NR2A/NR2B). Mol Pharmacol 51:79-86.

Luo J-H, Fu Z-Y, Losi G, Kim BG, Prybylowski K, Vissel B, Vicini S (2002) Functional expression of distinct NMDA channel subunits tagged with green fluorescent protein in hippocampal neurons in culture. Neuropharmacology 42:306-318.

Maletic-Savatic M, Malinow R, Svoboda K (1999) Rapid dendritic morphogenesis in CAl hippocampal dendrites induced by synaptic activity. Science 283:1923-1927.

Mammen AL, Huganir RL, O’Brien RJ (1997) Redistribution and stabilization of cell surface glutamate receptors during synapse formation. J Neurosci 17:7351-7358.

McIlhinney RA, Le Bourdelles B, Molnar E, Tricaud N, Streit P, Whiting PJ (1998) Assembly, intracellular targeting and cell surface expression of the human $\mathrm{N}$-methyl-D-aspartate receptor subunits NR1a and NR2A in transfected cells. Neuropharmacology 37:1355-1367.

Monyer H, Burnashev N, Laurie DJ, Sakmann B, Seeburg PH (1994) Developmental and regional expression in the rat brain and functional properties of four NMDA receptors. Neuron 12:529-540.

Noel J, Ralph GS, Pickard L, Williams JA, Molnar E, Uney JB, Collingridge GL, Henley JM (1999) Surface expression of AMPA receptors in hip- 
pocampal neurons is regulated by an NSF-dependent mechanism. Neuron 23:365-376.

Osten P, Srivastava S, Inman GJ, Vilim FS, Khatri L, Lee LM, States BA, Einheber S, Milner TA, Hanson PI, Ziff EB (1998) The AMPA receptor GluR2 C terminus can mediate a reversible, ATP-dependent interaction with NSF and alpha and beta SNAPs. Neuron 21:99-110.

Ozawa S, Kamiya H, Tsuzuki K (1998) Glutamate receptors in the mammalian central nervous system. Prog Neurobiol 54:581-618.

Rao A, Craig AM (1997) Activity regulates the synaptic localization of the NMDA receptor in hippocampal neurons. Neuron 19:801-812.

Roche KW, Standley S, McCallum J, Dune Ly C, Ehlers MD, Wenthold RJ (2001) Molecular determinants of NMDA receptor internalization. Nat Neurosci 4:794-802.

Sampo B, Kaech S, Kunz S, Banker G (2003) Two distinct mechanisms target membrane proteins to the axonal surface. Neuron 37:611-624.

Sans N, Prybylowski K, Petralia RS, Chang K, Wang Y-X, Racca C, Vicini S, Wenthold RJ (2003) NMDA receptor trafficking through an interaction between PDZ proteins and the exocyst complex. Nat Cell Biol 5:520-530.

Scheiffele P, Fan J, Choih J, Fetter R, Serafini T (2000) Neuroligin expressed in nonneuronal cells triggers presynaptic development in contacting axons. Cell 101:657-669.

Schiavo G, Santucci A, Dasgupta BR, Mehta PP, Jontes JD, Benfenati F, Wilson MC, Montecucco C (1993) Botulinum neurotoxins serotypes A and E cleave SNAP-25 at distinct COOH-terminal peptide bonds. FEBS Lett 335:99-103.

Scott DB, Blanpied TA, Swanson GT, Zhang C, Ehlers MD (2001) An NMDA receptor ER retention signal regulated by phosphorylation and alternative splicing. J Neurosci 21:3063-3072.

Setou M, Nakagawa T, Seog DH, Hirokawa N (2000) Kinesin superfamily motor protein KIF17 and mLin-10 in NMDA receptor-containing vesicle transport. Science 288:1796-1802.

Sollner T, Bennett MK, Whiteheart SW, Scheller RH, Rothman JE (1993) A protein assembly-disassembly pathway in vitro that may correspond to sequential steps of synaptic vesicle docking, activation and fusion. Cell 75:409-418.

Standley S, Roche KW, McCallum J, Sans N, Wenthold RJ (2000) PDZ domain suppression of an ER retention signal in NMDA receptor NR1 splice variants. Neuron 28:887-898.
Sytnyk V, Leshchyns'ka I, Delling M, Dityateva G, Dityatev A, Schachner M (2003) Neural cell adhesion molecule promotes accumulation of TGN organelles at sites of neuron-to-neuron contacts. J Cell Biol 159:649-661.

Tovar KR, Westbrook GL (1999) The incorporation of NMDA receptors with a distinct subunit composition at nascent hippocampal synapses in vitro. J Neurosci 19:4180-4188.

Vaidyanathan VV, Yoshino K, Jahnz M, Dorries C, Bade S, Nauenburg S, Niemann H, Binz T (1999) Proteolysis of SNAP-25 isoforms by botulinum neurotoxin types $\mathrm{A}, \mathrm{C}$ and $\mathrm{E}$ : domains and amino acid residues controlling the formation of enzyme-substrate complexes and cleavage. J Neurochem 72:327-337.

Verhage M, Maia AS, Plomp JJ, Brussaard AB, Heeroma JH, Vermeer H, Toonen RF, Hammer RE, van den Berg TK, Missler M, Geuze HJ, Südhof TC (2000) Synaptic assembly of the brain in the absence of neurotransmitter secretion. Science 287:864-869.

Washbourne P, Bortoletto N, Graham M, Wilson MC, Burgoyne RD, Montecucco C (1999) Botulinum neurotoxin E-insensitive mutants of SNAP-25 fail to bind VAMP but support exocytosis. J Neurochem 73:2424-2433.

Washbourne P, Thompson PM, Carta M, Costa ET, Mathews JR, LopesBendito G, Molnar Z, Becher MW, Valenzuela MW, Partridge LD, Wilson MC (2002a) Genetic ablation of the t-SNARE SNAP-25 distinguishes mechanisms of neuroexocytosis. Nat Neurosci 5:19-26.

Washbourne P, Bennett JE, McAllister AK (2002b) Rapid recruitment of NMDA receptor transport packets to nascent synapses. Nat Neurosci 5:751-759.

Wenthold RJ, Prybylowski K, Standley S, Sans N, Petralia RS (2003) Trafficking of NMDA receptors. Annu Rev Pharmacol Toxicol 43:335-358.

Wong WT, Wong RO (2000) Rapid dendritic movements during synapse formation and rearrangement. Curr Opin Neurobiol 10:118-124.

Xia H, Hornby ZD, Malenka RC (2001) An ER retention signal explains differences in surface expression of NMDA and AMPA receptor subunits. Neuropharmacology 41:714-723.

Young SH, Poo MM (1983) Spontaneous release of transmitter from growth cones of embryonic neurones. Nature 305:634-637.

Ziv NE, Garner CC (2001) Principles of glutamatergic synapse formation: seeing the forest for the trees. Curr Opin Neurobiol 11:536-543. 